\title{
Gene variants influencing measures of inflammation or predisposing to autoimmune and inflammatory diseases are not associated with the risk of type 2 diabetes
}

\author{
S. Rafiq $\cdot$ D. Melzer $\cdot$ M. N. Weedon $\cdot$ H. Lango $\cdot$ \\ R. Saxena $\cdot$ L. J. Scott $\cdot$ the DIAGRAM Consortium • \\ C. N. A. Palmer • A. D. Morris • M. I. McCarthy • \\ L. Ferrucci • A. T. Hattersley • E. Zeggini • \\ T. M. Frayling
}

Received: 2 June 2008 / Accepted: 18 August 2008 / Published online: 14 October 2008

(C) Springer-Verlag 2008

\begin{abstract}
Aims/hypothesis There are strong associations between measures of inflammation and type 2 diabetes, but the causal directions of these associations are not known. We tested the hypothesis that common gene variants known to alter circulating levels of inflammatory proteins, or known to alter autoimmune-related disease risk, influence type 2 diabetes risk.
\end{abstract}

Electronic supplementary material The online version of this article (doi:10.1007/s00125-008-1160-3) contains supplementary material, which is available to authorised users.

S. Rafiq · D. Melzer · M. N. Weedon $\cdot$ H. Lango

A. T. Hattersley $\cdot$ T. M. Frayling $(\bowtie)$

Peninsula Medical School, University of Exeter,

Magdalen Road,

Exeter EX1 2LU, UK

e-mail: Tim.Frayling@pms.ac.uk

\section{R. Saxena}

Department of Molecular Biology and Center

for Human Genetic Research, Massachusetts General Hospital,

Boston, MA, USA

\section{R. Saxena}

Medical and Population Genetics Program,

Broad Institute of Harvard and MIT,

Cambridge, MA, USA

\section{J. Scott}

Department of Biostatistics, School of Public Health, and Center for Statistical Genetics, University of Michigan,

Ann Arbor, MI, USA

\section{N. A. Palmer}

Population Pharmacogenetics Group, Biomedical Research Centre, Ninewells Hospital and Medical School,

University of Dundee,

Dundee, UK
Methods We selected 46 variants: (1) eight variants known to alter circulating levels of inflammatory proteins, including those in the IL18, IL1RN, IL6R, MIF, PAIl (also known as SERPINE1) and CRP genes; and (2) 38 variants known to predispose to autoimmune diseases, including type 1 diabetes. We tested the associations of these variants with type 2 diabetes using a meta-analysis of 4,107 cases and 5,187 controls from the Wellcome Trust Case Control

A. D. Morris

Diabetes Research Group, Division of Medicine and Therapeutics, Ninewells Hospital and Medical School, University of Dundee, Dundee, UK

M. I. McCarthy $\cdot$ E. Zeggini

Wellcome Trust Centre for Human Genetics, University of Oxford,

Oxford, UK

M. I. McCarthy

Oxford Centre for Diabetes, Endocrinology and Medicine,

University of Oxford, Churchill Hospital,

Oxford, UK

L. Ferrucci

Longitudinal Studies Section, Clinical Research Branch,

Gerontology Research Center, National Institute of Ageing, Baltimore, MA, USA 
Consortium, the Diabetes Genetics Initiative, and the Finland-United States Investigation of NIDDM studies. We followed up associated variants $(p<0.01)$ in a further set of 3,125 cases and 3,596 controls from the UK.

Results We found no evidence that inflammatory or autoimmune disease variants are associated with type 2 diabetes (at $p \leq 0.01$ ). The OR observed between the variant altering IL-18 levels, rs2250417, and type 2 diabetes (OR 1.00 [95\% CI 0.99-1.03]), is much lower than that expected given (1) the effect of the variant on IL-18 levels (0.28 SDs per allele); and (2) estimates, based on other studies, of the correlation between IL-18 levels and type 2 diabetes risk (approximate OR 1.15 [95\% CI 1.09-1.21] per 0.28 SD increase in IL-18 levels).

Conclusions/interpretation Our study provided no evidence that variants known to alter measures of inflammation, autoimmune or inflammatory disease risk, including type 1 diabetes, alter type 2 diabetes risk.

Keywords Autoimmune disease · Genes · Genetic epidemiology · Inflammation · Mendelian randomisation . SNP. Type 2 diabetes

$\begin{array}{ll}\text { Abbreviations } \\ \text { CRP } & \text { C-reactive protein } \\ \text { DGI } & \text { Diabetes Genetics Initiative } \\ \text { FUSION } & \text { Finland-United States Investigation of NIDDM } \\ \text { GWA } & \text { genome-wide association } \\ \text { IL-1RA } & \text { IL-1 receptor antagonist } \\ \text { MAF } & \text { minor allele frequency } \\ \text { MIF } & \text { macrophage migration inhibitory factor } \\ \text { PAI } & \text { plasminogen activator inhibitor } \\ \text { SIL-6R } & \text { soluble IL-6 receptor } \\ \text { SLE } & \text { systemic lupus erythematosus } \\ \text { SNP } & \text { single-nucleotide polymorphism } \\ \text { WTCCC } & \text { Wellcome Trust Case Control Consortium }\end{array}$

\section{Introduction}

Inflammatory and immunological factors are associated with type 2 diabetes, but the causal direction of this association is not known. Evidence for a possible causal role of inflammatory and immunological processes in type 2 diabetes comes from several sources. These include prospective studies that show raised levels of pro-inflammatory, and lower levels of anti-inflammatory, cytokines many years before the onset of type 2 diabetes [1]. Specific examples include the presence of raised circulating IL-18 [1] and macrophage migration inhibitory factor (MIF) [2] levels in the KORA study, where average follow-up time to diagnosis of type 2 diabetes is 10 years, and similar findings observed with raised $\mathrm{C}$-reactive protein (CRP) or
IL-6 levels in several other prospective studies [3-5]. Second, mouse knockout models of certain cytokine genes, including IL18, ILIRN, IL1A and IL1B, result in adverse effects on obesity and insulin resistance in mouse models [6-8]. For example, the $C D 11 B$ (also known as $M A C-1$ or ITGAM) knockout mouse is susceptible to diet-induced obesity compared with wild-type litter mates [9]. A common variant in the $C D 11 B$ gene has recently been established as a risk factor for systemic lupus erythematosus (SLE) [10], suggesting a possible link between autoimmune diseases and metabolic traits. Common variants in the CDKAL1 gene are associated with type 2 diabetes, psoriasis and Crohn's disease [11], although the associated polymorphisms are different and not correlated (in linkage disequilibrium) with each other. Finally, recent data indicating a critical role for IL-1 $\beta$ in beta cell function [12] have led to a small randomised controlled trial of recombinant human IL-1 receptor antagonist (IL-1RA) (anakinra) treatment in type 2 diabetes that showed improved beta cell function and reduced levels of markers of systemic inflammation in 35 anakinra-administered patients with type 2 diabetes [13].

Further evidence is needed to establish whether inflammation has a causal role in type 2 diabetes in humans. Observed changes in inflammatory protein levels/concentrations with disease progression may be secondary to early disease processes and knockout animal studies suggest that if inflammatory processes have a role it is more likely to be through obesity-induced changes. Genetics studies can add to the evidence for or against the causal role of a trait in disease. This is because genetic variants cannot be influenced by disease processes and are much less likely to be confounded than non-genetic factors. This principle of 'Mendelian randomisation' has been used before to indicate that raised CRP levels are likely to be a consequence rather than cause of continuous metabolic traits [14].

Detailed studies of genetic variation across genes encoding inflammatory proteins have identified an increasing number of common variants that alter circulating levels of these proteins. These include variants in or near the IL18 [15-17], IL1RN [17, 18], IL6R, PAII (also known as SERPINE1) [17, 19], $M I F$ [20] and $C R P$ genes [17, 21, 22], all associated with robust statistical confidence with levels of their respective protein products. In addition the variant in $I L 6 R$ is associated with IL-6 levels as well as levels of its soluble receptor (sIL-6R) [23, 24].

Recent genome-wide association (GWA) studies have resulted in a greatly increased knowledge of common gene variants that predispose to systemic or organ-specific autoimmune and inflammatory diseases. These include convincing genetic associations between variants at 30 loci, outside the HLA region, and Crohn's disease [25, 26], type 1 diabetes [27], rheumatoid arthritis [28, 29], coeliac disease [30, 31], ankylosing spondylitis [32], SLE [10, 33, 34] and 
multiple sclerosis $[32,35]$. Five of these loci include variants that alter the risk of more than one inflammatory disease.

It has been suggested that type 1 and type 2 diabetes share a partially overlapping aetiology [36] but there is mixed evidence to support this. Recent studies show that known type 2 diabetes variants in the TCF7L2 and FTO loci do not predispose to type 1 diabetes [37, 38] In contrast, a recent Scandinavian study indicates that individuals with adult latent autoimmune diabetes have an increased frequency of both type 1 and type 2 diabetes risk alleles [39].

In this study we aimed to provide further insight into the possible role of inflammatory and autoimmune processes in type 2 diabetes. To do this we tested the hypothesis that common gene variants known to alter either circulating levels of inflammatory proteins or autoimmune and inflammatory disease risk also alter the risk of type 2 diabetes.

\section{Methods}

\section{Study participants}

Initial type 2 diabetes GWA meta-analysis We used the $p$ values and ORs from a meta-analysis of three type 2 diabetes GWA scans (http:/www.well.ox.ac.uk/DIAGRAM/) that had recently been carried out using 2.2 million singlenucleotide polymorphisms (SNPs) (directly typed and imputed) with 4,107 type 2 diabetes cases and 5,187 controls, to identify associations between the selected polymorphisms and type 2 diabetes. The meta-analysis included samples used in GWA scans from the Wellcome Trust Case Control Consortium (WTCCC) (1,924 type 2 diabetes cases and 2,938 population controls, all from the UK), the Diabetes Genetics Initiative (DGI) (1,022 type 2 diabetes cases and 1,075 matched controls and 326 sibships discordant for diabetes) and the Finland-United States Investigation of NIDDM Genetics (FUSION) (1,161 type 2 diabetes cases and 1,174 normal glucose-tolerant controls, from Finland) studies [40]. Each SNP passed quality control criteria in each individual type 2 diabetes GWA study, as recently described [40]. Each study analysed the data under a model that is additive on the log-odds scale. ORs from each sample, excluding the DGI sibships, were combined using a fixed-effects model [41]. Patients in the WTCCC and DGI studies positive for anti-GAD antibodies were not included $[40,42]$. The FUSION GWA case sample is composed of 789 cases from FUSION and 372 cases from FINRISK 2002. FUSION cases were excluded if they were positive for anti-GAD antibodies, had a short time to onset of insulin treatment following diagnosis, or had known or probable type 1 diabetes first-degree relatives [43]. Brief details of study participants are given in Electronic supplementary material (ESM) Table 1.
Replication study participants For replication we genotyped SNPs nominally associated with type 2 diabetes using the UK Type 2 Diabetes Genetics Consortium Collection of 3,125 cases and 3,596 controls. All study participants were recruited from the Tayside region in Dundee, Scotland and were of European origin. Cases with monogenic forms of diabetes or with a history of treatment with regular insulin therapy within 1 year of diagnosis were excluded [44]. Controls were restricted to individuals $<80$ years of age and participants with evidence of hyperglycaemia were excluded from the study [44]. Details are given in ESM Table 1.

\section{SNP selection}

We selected three sets of SNPs from previous studies that have either been directly genotyped [28, 30-32, 35, 40, 42, 43] or imputed in the three-study diabetes meta-analysis [40]. These included: (1) Eight SNPs previously associated with circulating IL-1RA [17, 18], sIL-6R [24, 45], IL-18 [16, 17], CRP [17], plasminogen activator inhibitor (PAI)-1 [19] or MIF levels [20]. All SNPs were 'cis' effects in that they were present in or near the gene that codes for the protein they are associated with. This together with the statistical confidence $\left(p \leq 10^{-5}\right)$ of the associations between the SNP and protein levels means the associations are very unlikely to be false-positive results. For $I L I R N$ and $I L 18$ genes [16-18] there is evidence for two independent association signals $\left(r^{2}\right.$ between variants $\left.<0.5\right)$ and we therefore included both the SNPs associated with respective protein levels in each case. (2) Seven SNPs from five loci: IL23R, PTPN2, PTPN22, SH2B3 and IL2RA, which are associated with more than one inflammatory/autoimmune disease [25-27, 29, 31, 32, 35]. (3) Thirty-one independently associated variants from 30 loci proven to be autoimmune disease risk variants after robust replications (overall $p \leq$ $10^{-8}$ ) and excluding the SNPs in the MHC locus. These SNPs are associated with seven diseases (Crohn's disease, type 1 diabetes, rheumatoid arthritis, coeliac disease, ankylosing spondylitis, SLE and multiple sclerosis).

All the 46 SNPs tested for an association passed QC control criteria in each individual study, as recently described [40]. Briefly all SNPs below a minor allele frequency (MAF) of $1 \%$ were excluded from analysis and all genotyped SNPs were in Hardy-Weinberg equilibrium in each individual study $\left(p>10^{-4}\right.$ for WTCCC, $p \geq 10^{-6}$ for DGI and $p \geq 10^{-6}$ for FUSION). Where genotyping data were unavailable, imputed SNPs were used for analysis as has previously been described [40]. In total 54\% (25), 50\% (23) and 52\% (24) of the tested 46 SNPs lacked direct genotype information in the FUSION, WTCCC and DGI studies, respectively, and were therefore imputed. All imputed SNPs, except in five situations, had quality scores $\left(r^{2}\right.$ hat in DGI and FUSION, 
imputation information scores in WTCCC) $>80 \%$ and all, except in 17 situations, had quality scores $>90 \%$.

Individual genotyping in the replication study

We used a $p$ value of $<0.01$ in the three-way meta-analysis to take SNPs forward into the replication samples. The exception to this was SNPs in the ILIRN and IL18 genes, where we used the less stringent $p<0.1$. SNPs in these two genes influence circulating levels and have a stronger prior case for their products' involvement in type 2 diabetes given previous trial and prospective studies. Genotyping was performed by KBiosciences (Hoddesdon, UK) using their own system of fluorescence-based competitive allelespecific PCR (KASPar).

\section{Statistics}

Meta-analysis of $p$ values using an additive effects model in WTCCC, DGI and FUSION samples has been previously described [40]. The ORs were calculated excluding the related component of the DGI study. To combine the previously published meta-analysis data with replication data we performed a meta-analysis using a fixed-effects inverse variance method using the summary ORs and $95 \%$ CIs from the three-way analysis as one study and the ORs and $95 \%$ CIs from the replication samples as a second study. This meta-analysis was performed using the 'Metan' module in STATA version 9.1. In the three-study metaanalysis we had $80 \%$ power to detect an OR of 1.20 for a SNP with a MAF of 0.09 (the lowest MAF of all 46 SNPs) at $p=0.05$. For a more common SNP $(\mathrm{MAF}=0.30)$ we had $80 \%$ power to detect an OR of 1.10 at $p=0.05$. Power calculations were performed using STATA version 9.1.

Sensitivity analysis using directly genotyped SNPs

For 34 of the 46 SNPs the direct genotypes, or direct genotypes at an $r^{2}>0.8$ proxy, were available in the WTCCC and DGI studies (total 2,946 cases and 4,013 controls typed on the Affymetrix $500 \mathrm{~K}$ chip). For eight of these 34 SNPs the $r^{2}>0.8$ proxy was also available in FUSION. To confirm that the use of imputed data was not substantially influencing our results, we therefore repeated the analyses using only directly genotyped variants for these 34 SNPs.

Estimating expected effect sizes of inflammatory protein variants on type 2 diabetes risk

We calculated the approximate effect size we would expect a SNP that alters inflammatory protein levels to have on the risk of type 2 diabetes, if the inflammatory protein is causal to type 2 diabetes. We used the triangulation approach outlined in Fig. 1 to (1) estimate the expected per allele effect of a SNP on type 2 diabetes risk (A in Fig. 1), given (2) the per allele effect of the SNP on inflammatory protein levels (B in Fig. 1), and (3) the correlation between inflammatory protein levels and type 2 diabetes (C in Fig. 1). We did not have measures of inflammatory-related proteins in our cases and controls and so we used data from previous studies to obtain approximate effect sizes. For example, each allele of rs2250417, in the IL18 gene, raises IL-18 levels by $0.28 \mathrm{SDs}$ in the InCHIANTI study [17]. In the same study, a $0.28 \mathrm{SD}(68 \mathrm{pg} / \mathrm{ml})$ rise in IL-18 levels is associated with an OR of 1.15 (95\% CI 1.09-1.21) for type 2 diabetes risk (L. Ferrucci, unpublished results). The prospective KORA study of type 2 diabetes showed that individuals in the top quartile of IL-18 levels, had IL-18 levels $242 \mathrm{pg} / \mathrm{ml}$ higher than those in the bottom quartile [46], and a risk ratio for type 2 diabetes of $1.96(95 \% \mathrm{CI}$ 1.49-2.58). Using these figures we calculated that an allele effect of $68 \mathrm{pg} / \mathrm{ml}$ will equate to an approximate expected effect of a risk ratio of 1.21 (95\% CI 1.12-1.30) for type 2 diabetes. Similar calculations using the previously reported effect of rs8192284 in the IL6R gene on IL-6 levels [24] and risk estimates from prospective studies of IL-6 with type 2 diabetes [47], suggest we would expect an approximate per allele effect of rs8192284 of 1.06 (95\% CI 1.04 1.08) for type 2 diabetes risk. Using the previously reported effect of rs 12093699 in the CRP gene on CRP levels [17] and risk estimates from prospective studies of CRP with type 2 diabetes [5] we would expect an approximate per allele effect

(C) Odds ratio $1.15(1.09-1.21)$

per 0.28 SDs (InCHIANTI)

Risk ratio $1.21(1.12-1.30)$

for equivalent rise (KORA)

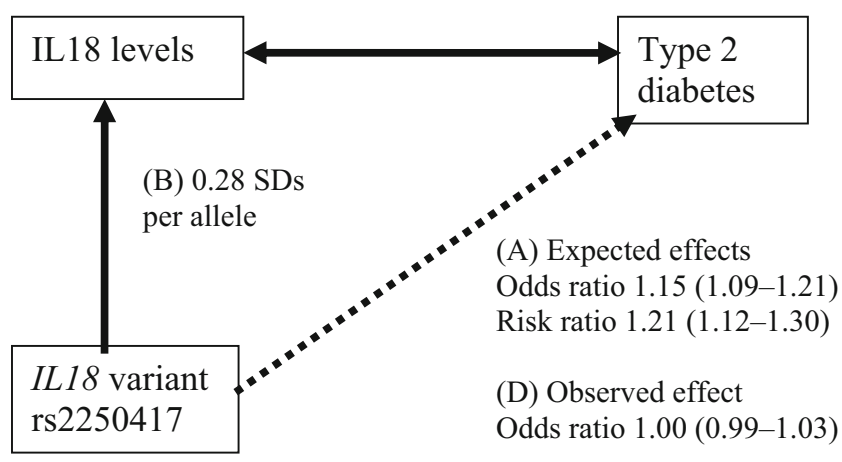

Fig. 1 Associations between the SNP rs2250417 and IL-18 levels, IL-18 levels and type 2 diabetes and the expected and observed effects of rs 2250417 on type 2 diabetes. ORs and risk ratios for the IL-18 levels-type 2 diabetes association are those estimated for a $0.28 \mathrm{SD}$ increase in IL-18 levels, the effect of rs2250417 on IL-18 levels, from the InCHIANTI [17] and KORA studies [46]. Odds ratios and risk ratios are shown with $95 \% \mathrm{CIs}$ 
of rs12093699 of a risk ratio of 1.34 (95\% CI 1.23-1.39) for type 2 diabetes risk (ESM Table 2). These estimates are very approximate because they use circulating measures from different studies. In the case of prospective studies, estimates are based on risk ratios rather than ORs but the incidence of type 2 diabetes $(5-10 \%)$ means that risk ratios and ORs will be approximately equivalent.

\section{Results}

SNPs known to alter circulating levels of inflammatory proteins

We found no strong evidence that eight SNPs, robustly associated with circulating levels of inflammatory proteins, alter the risk of type 2 diabetes. Associations with type 2 diabetes risk for two SNPs, one in each of the ILI8 and $I L 1 R N$ genes, reached $p<0.1$ in the three-study metaanalysis. The protein products of these two genes have both been strongly implicated in type 2 diabetes in trial and prospective studies and so we assigned a less-stringent statistical threshold for follow-up. At the time of study the SNP in each of these genes that represented the strongest association with circulating levels was uncertain. We therefore decided to increase the confidence of our genetic association findings (negative or positive) by increasing the sample size for all four SNPs in IL1RN and IL18. Metaanalysis using a total GWA and replication sample of 7,232 cases and 8,783 controls showed no strong evidence of association (Table 1). Subsequent analysis [17] indicated that rs2250417 had the strongest association with circulating IL-18 levels. The OR observed between the IL-18altering variant, rs2250417, and type 2 diabetes is 1.00 (95\% CI 0.99-1.03) (Fig. 1d). This is much lower than that expected given (1) the effect of the variant on IL-18 levels
(0.28 SDs per allele [17]), and (2) estimates, based on other studies, of the correlation between IL-18 levels and type 2 diabetes risk, which are 1.15 (95\% CI 1.09-1.21) per 0.28 SD increase in IL-18 levels in the InCHIANTI study (L. Ferrucci, unpublished results), and a risk ratio of 1.21 (95\% CI 1.12-1.30) based on the KORA prospective study [46] (Fig. 1).

All ORs and $p$ values from the meta-analysis are given in Table 1. The upper $95 \%$ CIs for risk alleles did not exceed 1.10. There was no evidence of association when limiting the analysis to the directly genotyped proxies, which captured six of the eight SNPs through directly genotyped proxies at $r^{2}>0.8$, in the WTCCC and DGI studies (ESM Table 3).

SNPs known to alter the risk of autoimmune diseases

We found no strong evidence that SNPs robustly associated with multiple autoimmune diseases alter the risk of type 2 diabetes. ORs and $p$ values from the three-study metaanalysis are given in Table 2. The upper 95\% CIs for risk alleles did not exceed 1.12. We found no strong evidence that SNPs robustly associated with individual autoimmune diseases, including type 1 diabetes, alter the risk of type 2 diabetes. ORs and $p$ values from the three-study metaanalysis are given in Table 3. The upper 95\% CIs for risk alleles did not exceed 1.19. There was also no evidence of association when limiting the analysis to directly genotyped proxies, which captured 28 of the 38 SNPs at $r^{2}>0.8$ in the WTCCC and DGI studies (ESM Table 3).

\section{Discussion}

We have found no evidence that common gene variants known to alter circulating levels of inflammatory proteins, or

Table 1 Cytokine cis-effect SNPs and associations with type 2 diabetes: three-way meta-analysis results across WTCCC, DGI and FUSION studies

\begin{tabular}{|c|c|c|c|c|c|c|c|c|c|c|c|}
\hline \multirow[t]{2}{*}{$\begin{array}{l}\text { Disease } \\
\text { SNP }\end{array}$} & \multirow[t]{2}{*}{ Gene } & \multirow[t]{2}{*}{$\begin{array}{l}\text { Total } \\
\text { cases }\end{array}$} & \multirow[t]{2}{*}{$\begin{array}{l}\text { Total } \\
\text { controls }\end{array}$} & \multirow[t]{2}{*}{ MAF } & \multicolumn{3}{|l|}{ Imputed } & \multicolumn{4}{|c|}{$\begin{array}{l}\text { OR for developing type } 2 \text { diabetes given } \\
\text { pro-inflammatory allele }(95 \% \mathrm{CI})\end{array}$} \\
\hline & & & & & WTCCC & DGI & FUSION & Stage 1 & $p$ value & $\begin{array}{l}\text { Stage } 2 \text { (including } \\
\text { replication samples) }\end{array}$ & $p$ value \\
\hline rs4251961 & $I L 1 R N$ & 7,493 & 8,949 & 0.40 & No & No & Yes & $1.06(0.99-1.12)$ & 0.07 & $1.01(0.99-1.03)$ & 0.28 \\
\hline rs6761276 & $I L 1 R N$ & 7,888 & 8,484 & 0.44 & Yes & Yes & No & $0.98(0.92-1.05)$ & 0.60 & $1.00(0.99-1.03)$ & 0.39 \\
\hline rs2250417 & ILI8 & 7,674 & 9,175 & 0.47 & Yes & Yes & No & $1.00(0.95-1.07)$ & 0.87 & $1.00(0.99-1.03)$ & 0.39 \\
\hline rs5744256 & IL18 & 7,479 & 8,509 & 0.21 & Yes & Yes & Yes & $1.08(1.01-1.15)$ & 0.03 & $1.03(1.00-1.05)$ & 0.03 \\
\hline rs8192284 & $I L 6 R$ & 4,549 & 5,579 & 0.35 & Yes & Yes & Yes & $0.96(0.90-1.02)$ & 0.18 & & \\
\hline rs12093699 & $C R P$ & 4,549 & 5,579 & 0.32 & Yes & Yes & No & $1.02(0.96-1.09)$ & 0.52 & & \\
\hline rs2227631 & PAII & 4,549 & 5,579 & 0.40 & Yes & Yes & No & $0.97(0.91-1.0)$ & 0.45 & & \\
\hline rs1007888 & MIF & 4,549 & 5,579 & 0.42 & Yes & Yes & Yes & $0.96(0.90-1.02)$ & 0.19 & & \\
\hline
\end{tabular}

For ILIRN and IL18 genes, data from the replication study are included in the meta-analysis 
Table 2 Pleiotropic autoimmune disease SNPs and their associations with type 2 diabetes: three-way meta-analysis results across WTCCC, DGI and FUSION studies

\begin{tabular}{|c|c|c|c|c|c|c|c|c|}
\hline \multirow[t]{2}{*}{ Disease SNP } & \multirow[t]{2}{*}{ Disease } & \multirow[t]{2}{*}{ Gene } & \multicolumn{3}{|l|}{ Imputed } & \multirow{2}{*}{$\begin{array}{l}\text { Disease risk } \\
\text { allele frequency } \\
\text { HapMap-CEPH }\end{array}$} & \multirow{2}{*}{$\begin{array}{l}\text { Meta-analysis OR } \\
\text { for developing type } \\
2 \text { diabetes given disease } \\
\text { risk allele }(95 \% \mathrm{CI})\end{array}$} & \multirow{2}{*}{$\begin{array}{l}\text { OR } \\
p \text { value }\end{array}$} \\
\hline & & & WTCCC & DGI & FUSION & & & \\
\hline rs 11209032 & Ankylosing spondylitis & $I L 23 R$ & Yes & Yes & No & 0.31 & $0.96(0.89-1.02)$ & 0.16 \\
\hline rs11805303 & Crohn's disease & $I L 23 R$ & No & No & Yes & 0.29 & $0.93(0.87-0.99)$ & 0.04 \\
\hline rs 2542151 & Crohn's disease and type 1 diabetes & PTPN2 & No & No & Yes & 0.19 & $0.94(0.87-1.02)$ & 0.17 \\
\hline rs6679677 & $\begin{array}{l}\text { Rheumatoid arthritis, Crohn's disease } \\
\text { and type } 1 \text { diabetes }\end{array}$ & PTPN22 & No & No & Yes & 0.14 & $1.02(0.93-1.12)$ & 0.69 \\
\hline rs2104286 & Type 1 diabetes and multiple sclerosis & $I L 2 R A$ & No & No & Yes & 0.23 & $1.01(0.94-1.08)$ & 0.79 \\
\hline rs 17696736 & Type 1 diabetes and coeliac disease & SH2B3 & No & No & Yes & 0.35 & $1.03(0.97-1.09)$ & 0.66 \\
\hline rs653178 & Type 1 diabetes and coeliac disease & SH2B3 & Yes & Yes & Yes & 0.41 & $1.00(0.94-1.06)$ & 0.99 \\
\hline
\end{tabular}

Hapmap CEPH refers to individuals of European ancestry typed in the International Hapmap project

those robustly associated with autoimmune or inflammatorybased diseases, influence risk of type 2 diabetes. We have not corrected for multiple testing because, given that our results are consistent with no association, this would be anticonservative, rather than conservative. We included variants that influence inflammatory protein levels that are altered many years before the onset of diabetes. Included in our study were variants known to alter IL-1RA levels. This inflammatory protein is of particular interest because administration of recombinant human IL-1RA (anakinra) in a recent parallel group trial improved beta cell function in type 2 diabetic patients. However, we found no evidence that lifetime exposure to slightly lower IL-1RA levels, as determined by $I L 1 R N$ genotypes, predisposes to type 2 diabetes.

Our results are consistent with chronic inflammation being secondary to type 2 diabetes disease processes rather than being causal. This does not rule out a role for other inflammatory or autoimmune processes, for which there is no known genetic variant. There are a number of limitations to our study. The main limitation is that we have not measured inflammatory proteins in our cases and controls. This means that we cannot perform a formal Mendelian randomisation analysis, where it is preferable to have the SNP, inflammatory protein levels and disease status measured in the same study. However, using data from other studies we estimated that variants that alter IL-18, IL-6 and CRP levels should predispose to type 2 diabetes with ORs of approximately 1.15 to $>1.21,1.06$ and 1.34 , respectively (ESM Table 2), if these pro-inflammatory proteins are causally related to type 2 diabetes. The upper $95 \%$ CI of the effect sizes we observed $(1.05,1.02$ and 1.09 for IL18, IL6R and CRP variants, respectively) are lower than the expected effect size. This is consistent with raised IL-18, IL-6 and CRP levels being secondary to, rather than causally predisposing to, type 2 diabetes. Further studies are needed with measures of inflammatory proteins in large numbers of cases and controls. It is also possible that these variants are not altering inflammatory pathways even if they are altering circulating levels.

A second limitation is that variants known to alter the risk of autoimmune and inflammatory diseases may not have an inflammatory effect in the general population. However, the identification of variants associated with inflammatory and autoimmune-related diseases indicates that the variant may be altering the expression, processing or function of a nearby gene that is critical to an inflammatory or autoimmune process prior to disease onset. Most of the autoimmune disease-associated variants have only been discovered very recently and so the disease mechanisms are not completely understood. However, early studies indicate that the variant in the IL2RA region predisposing to type 1 diabetes and multiple sclerosis alters circulating levels of IL2RA protein [48], the variant predisposing to coeliac disease in the IL18RAP locus alters mRNA levels of IL-18 receptor accessory protein in lymphocytes [31] and the variant in the $I L 7 R A$ (also known as $I L 7 R$ ) gene predisposing to multiple sclerosis alters levels of soluble IL-7 receptor antagonist because of differential splicing of a key exon [49]. It is also suggested that the variant predisposing to ankylosing spondylitis in the ARTS1 (also known as ERAP-1) gene may have a general pro-inflammatory effect because it cleaves cell surface receptors for IL-1, IL-6 and TNF- $\alpha$ [32].

A final possible limitation is that we have used imputed SNP genotypes for association analysis for the majority of the 46 studied variants. However, this is unlikely to have resulted in appreciable differences in OR estimates, as has previously been shown $[40,50]$ and there were no positive associations when we used the strongest available directly genotyped proxies $\left(r^{2}>0.8\right)$ instead of the imputed SNPs (ESM Table 3). 
Table 3 Autoimmune disease SNPs and their associations with type 2 diabetes: three-way meta-analysis results across WTCCC, DGI and FUSION studies

\begin{tabular}{|c|c|c|c|c|c|c|c|c|}
\hline \multirow{2}{*}{$\begin{array}{l}\text { Disease } \\
\text { SNP }\end{array}$} & \multirow[t]{2}{*}{ Disease group } & \multirow[t]{2}{*}{ Gene } & \multicolumn{3}{|l|}{ Imputed } & \multirow{2}{*}{$\begin{array}{l}\text { Disease risk } \\
\text { allele frequency } \\
\text { HapMap-CEPH }\end{array}$} & \multirow{2}{*}{$\begin{array}{l}\text { Meta-analysis OR } \\
\text { for developing } \\
\text { type } 2 \text { diabetes } \\
\text { given disease risk } \\
\text { allele }(95 \% \mathrm{CI})\end{array}$} & \multirow{2}{*}{$\begin{array}{l}p \text { value } \\
\text { for OR }\end{array}$} \\
\hline & & & WTCCC & DGI & FUSION & & & \\
\hline Rs30187 & $\begin{array}{c}\text { Ankylosing } \\
\text { spondylitis }\end{array}$ & ARTS1 & Yes & Yes & No & 0.30 & $0.99(0.93-1.05)$ & 0.81 \\
\hline rs6822844 & Coeliac disease & $\begin{array}{l}\text { IL21, IL2, TENR (also known } \\
\text { as ADAD1), KIAA1109 }\end{array}$ & Yes & Yes & No & 0.79 & $1.02(0.94-1.11)$ & 0.64 \\
\hline rs2816316 & Coeliac disease & RGS1 & Yes & Yes & No & 0.78 & $1.02(0.94-1.10)$ & 0.68 \\
\hline rs13015714 & Coeliac disease & $\begin{array}{l}\text { IL1RL1, IL18R1, IL18RAP, } \\
\text { SLC9A4 }\end{array}$ & Yes & Yes & No & 0.23 & $1.05(0.97-1.12)$ & 0.22 \\
\hline rs17810546 & Coeliac disease & $I L 12 A$ & Yes & Yes & No & 0.10 & $1.03(0.94-1.13)$ & 0.50 \\
\hline rs1464510 & Coeliac disease & $L P P$ & Yes & Yes & No & 0.57 & $1.02(0.96-1.08)$ & 0.51 \\
\hline rs1738074 & Coeliac disease & $T A G A P$ & Yes & Yes & No & 0.49 & $1.00(0.94-1.07)$ & 0.88 \\
\hline rs10883365 & Crohn's disease & $N K X 2-3$ & No & No & Yes & 0.50 & $0.98(0.92-1.03)$ & 0.41 \\
\hline rs2241880 & Crohn's disease & $A T G 16 L 1$ & Yes & Yes & No & 0.54 & $0.98(0.93-1.04)$ & 0.60 \\
\hline rs10077785 & Crohn's disease & IBD5 & No & No & Yes & 0.75 & $0.96(0.89-1.02)$ & 0.20 \\
\hline rs10801047 & Crohn's disease & Chr 1q31 & No & No & Yes & 0.09 & $1.06(0.95-1.19)$ & 0.27 \\
\hline rs6596075 & Crohn's disease & Chr 5q31 & No & No & Yes & 0.83 & $1.03(0.95-1.17)$ & 0.50 \\
\hline rs12035082 & Crohn's disease & Chr 1q24 & No & No & Yes & 0.37 & $0.99(0.94-1.06)$ & 0.88 \\
\hline rs2836754 & Crohn's disease & Chr 21q22 & No & No & Yes & 0.65 & $0.97(0.92-1.04)$ & 0.42 \\
\hline rs17221417 & Crohn's disease & $\begin{array}{l}\text { CARD15 (also known as } \\
\text { NOD2) }\end{array}$ & No & No & Yes & 0.36 & $1.07(0.99-1.15)$ & 0.05 \\
\hline rs4958847 & Crohn's disease & $I R G M$ & No & No & No & 0.09 & $1.06(0.96-1.15)$ & 0.24 \\
\hline rs9858542 & Crohn's disease & Chr $3 \mathrm{p} 21$ & No & No & Yes & 0.24 & $0.99(0.93-1.05)$ & 0.66 \\
\hline rs17234657 & Crohn's disease & Chr 5p13 & No & No & Yes & 0.17 & $1.06(0.97-1.15)$ & 0.18 \\
\hline rs10761659 & Crohn's disease & Chr 10q21 & No & No & Yes & 0.45 & $0.96(0.91-1.02)$ & 0.22 \\
\hline rs6920220 & $\begin{array}{l}\text { Rheumatoid } \\
\text { arthritis }\end{array}$ & Chr 6q23 & No & No & Yes & 0.17 & $1.05(0.98-1.13)$ & 0.17 \\
\hline rs10499194 & $\begin{array}{l}\text { Rheumatoid } \\
\text { arthritis }\end{array}$ & Chr 6q23 & Yes & Yes & Yes & 0.82 & $1.03(0.96-1.10)$ & 0.41 \\
\hline rs12708716 & Type 1 diabetes & $\begin{array}{c}K I A A 0350 \text { (also known as } \\
C L E C 16 A) \text { Chr } 16 \mathrm{p} 13\end{array}$ & No & Yes & Yes & 0.29 & $1.03(0.97-1.10)$ & 0.31 \\
\hline rs763361 & Type 1 diabetes & $C D 226$ & Yes & Yes & No & 0.47 & $0.94(0.88-0.99)$ & 0.04 \\
\hline rs3788964 & Type 1 diabetes & $I F I H 1$ & No & No & No & 0.86 & $0.95(0.87-1.02)$ & 0.17 \\
\hline rs2292239 & Type 1 diabetes & $E R B B 3$ & No & No & Yes & 0.30 & $0.97(0.91-1.04)$ & 0.45 \\
\hline rs3087243 & Type 1 diabetes & CTLA4 & No & No & Yes & 0.54 & $0.98(0.92-1.04)$ & 0.46 \\
\hline rs6897932 & $\begin{array}{l}\text { Multiple } \\
\text { sclerosis }\end{array}$ & $I L 7 R A$ & No & No & No & 0.76 & $1.03(0.96-1.10)$ & 0.35 \\
\hline rs6445975 & SLE & $P X K$ & Yes & Yes & No & 0.21 & $1.01(0.95-1.08)$ & 0.73 \\
\hline rs 12537284 & SLE & IRF5, TNPO3 & Yes & Yes & No & 0.16 & $1.07(0.98-1.16)$ & 0.11 \\
\hline rs4963128 & SLE & $\begin{array}{l}\text { KIAA1542 (also known as } \\
\text { PHRF1) }\end{array}$ & Yes & Yes & No & 0.65 & $1.00(0.94-1.08)$ & 0.89 \\
\hline rs9888739 & SLE & $I T G A M$ & Yes & Yes & No & 0.11 & $1.03(0.94-1.14)$ & 0.51 \\
\hline
\end{tabular}

Hapmap CEPH refers to individuals of European ancestry typed in the International Hapmap project

A further implication of our study is that it does not support the hypothesis of a genetic overlap between type 1 and type 2 diabetes. Our results are consistent with the recent studies which show that the known type 2 diabetesand BMI-associated variants in the TCF7L2 [37] and FTO [38] genes do not predispose to type 1 diabetes.
In conclusion, in a large case-control study of type 2 diabetes, we tested 46 SNPs associated with inflammatory diseases or inflammatory protein levels, and identified no associations with type 2 diabetes. Our study is consistent with inflammatory processes being secondary, rather than causal, to type 2 diabetes. 
Acknowledgements M. N. Weedon is a Vandervell Foundation research fellow. The FUSION study was funded by an intramural grant (NIH DK 062370) from the US National Institutes of Health (NIH). E. Zeggini is a Wellcome Trust Career Development Fellow. D. Melzer's work is supported in part by NIH/National Institute on Aging (NIH/NIA) Grant R01 AG24233. Details of the DIAGRAM (Diabetes Genetics Replication And Meta-analysis) Consortium can be found at http://www. well.ox.ac.uk/DIAGRAM/index.html.

Duality of interest The authors declare that there is no duality of interest associated with this manuscript.

\section{References}

1. Kolb H, Mandrup-Poulsen T (2005) An immune origin of type 2 diabetes. Diabetologia 48:1038-1050

2. Herder C, Kolb H, Koenig W et al (2006) Association of systemic concentrations of macrophage migration inhibitory factor with impaired glucose tolerance and type 2 diabetes: results from the Cooperative Health Research in the Region of Augsburg, Survey 4 (KORA S4). Diabetes Care 29:368-371

3. Duncan BB, Schmidt MI, Pankow JS et al (2003) Low-grade systemic inflammation and the development of type 2 diabetes: the atherosclerosis risk in communities study. Diabetes 52:1799-1805

4. Barzilay JI, Abraham L, Heckbert SR et al (2001) The relation of markers of inflammation to the development of glucose disorders in the elderly: the Cardiovascular Health Study. Diabetes 50: 2384-2389

5. Spranger J, Kroke A, Mohlig M et al (2003) Inflammatory cytokines and the risk to develop type 2 diabetes: results of the prospective population-based European Prospective Investigation into Cancer and Nutrition (EPIC)-Potsdam Study. Diabetes 52:812-817

6. Netea MG, Joosten LA, Lewis E et al (2006) Deficiency of interleukin-18 in mice leads to hyperphagia, obesity and insulin resistance. Nat Med 12:650-656

7. Matsuki T, Horai R, Sudo K, Iwakura Y (2003) IL-1 plays an important role in lipid metabolism by regulating insulin levels under physiological conditions. J Exp Med 198:877-888

8. Chida D, Osaka T, Hashimoto O, Iwakura Y (2006) Combined interleukin-6 and interleukin-1 deficiency causes obesity in young mice. Diabetes 55:971-977

9. Dong ZM, Gutierrez-Ramos JC, Coxon A, Mayadas TN, Wagner DD (1997) A new class of obesity genes encodes leukocyte adhesion receptors. Proc Natl Acad Sci U S A 94:7526-7530

10. Nath SK, Han S, Kim-Howard X et al (2008) A nonsynonymous functional variant in integrin-alpha(M) (encoded by ITGAM) is associated with systemic lupus erythematosus. Nat Genet 40:152-154

11. Wolf N, Quaranta M, Prescott NJ et al (2008) Psoriasis is associated with pleiotropic susceptibility loci identified in type II diabetes and Crohn disease. J Med Genet 45:114-116

12. Donath MY, Storling J, Maedler K, Mandrup-Poulsen T (2003) Inflammatory mediators and islet beta-cell failure: a link between type 1 and type 2 diabetes. J Mol Med 81:455-470

13. Larsen CM, Faulenbach M, Vaag A et al (2007) Interleukin-1-receptor antagonist in type 2 diabetes mellitus. N Engl J Med 356:1517-1526

14. Timpson NJ, Lawlor DA, Harbord RM et al (2005) C-reactive protein and its role in metabolic syndrome: Mendelian Randomisation Study. Lancet 366:1954-1959

15. Tiret L, Godefroy T, Lubos E et al (2005) Genetic analysis of the interleukin-18 system highlights the role of the interleukin-18 gene in cardiovascular disease. Circulation 112:643-650

16. Frayling TM, Rafiq S, Murray A et al (2007) An interleukin-18 polymorphism is associated with reduced serum concentrations and better physical functioning in older people. J Gerontol A Biol Sci Med Sci 62:73-78

17. Melzer D, Perry JR, Hernandez D et al (2008) A genome-wide association study identifies protein quantitative trait loci (pQTLs). PLoS Genet 4:e1000072

18. Rafiq S, Stevens K, Hurst AJ et al (2007) Common genetic variation in the gene encoding interleukin-1-receptor antagonist (IL-1RA) is associated with altered circulating IL-1RA levels. Genes Immun 8:344-351

19. Kathiresan S, Gabriel SB, Yang Q et al (2005) Comprehensive survey of common genetic variation at the plasminogen activator inhibitor-1 locus and relations to circulating plasminogen activator inhibitor-1 levels. Circulation 112:1728-1735

20. Herder C, Klopp N, Baumert J et al (2008) Effect of macrophage migration inhibitory factor (MIF) gene variants and MIF serum concentrations on the risk of type 2 diabetes: results from the MONICA/KORA Augsburg Case-Cohort Study, 1984-2002. Diabetologia 51:276-284

21. Russell AI, Cunninghame Graham DS, Shepherd C et al (2004) Polymorphism at the C-reactive protein locus influences gene expression and predisposes to systemic lupus erythematosus. Hum Mol Genet 13:137-147

22. Zee RY, Ridker PM (2002) Polymorphism in the human Creactive protein (CRP) gene, plasma concentrations of CRP, and the risk of future arterial thrombosis. Atherosclerosis 162:217-219

23. Reich D, Patterson N, Ramesh V et al (2007) Admixture mapping of an allele affecting interleukin 6 soluble receptor and interleukin 6 levels. Am J Hum Genet 80:716-726

24. Rafiq S, Frayling TM, Murray A et al (2007) A common variant of the interleukin 6 receptor (IL-6r) gene increases IL-6r and IL-6 levels, without other inflammatory effects. Genes Immun 8:552559

25. Parkes M, Barrett JC, Prescott NJ et al (2007) Sequence variants in the autophagy gene IRGM and multiple other replicating loci contribute to Crohn's disease susceptibility. Nat Genet 39:830-832

26. Rioux JD, Xavier RJ, Taylor KD et al (2007) Genome-wide association study identifies new susceptibility loci for Crohn disease and implicates autophagy in disease pathogenesis. Nat Genet 39:596-604

27. Todd JA, Walker NM, Cooper JD et al (2007) Robust associations of four new chromosome regions from genome-wide analyses of type 1 diabetes. Nat Genet 39:857-864

28. Thomson W, Barton A, Ke X et al (2007) Rheumatoid arthritis association at 6q23. Nat Genet 39:1431-1433

29. Plenge RM, Cotsapas C, Davies L et al (2007) Two independent alleles at $6 \mathrm{q} 23$ associated with risk of rheumatoid arthritis. Nat Genet 39:1477-1482

30. van Heel DA, Franke L, Hunt KA et al (2007) A genome-wide association study for celiac disease identifies risk variants in the region harboring IL-2 and IL-21. Nat Genet 39:827-829

31. Hunt KA, Zhernakova A, Turner G et al (2008) Newly identified genetic risk variants for celiac disease related to the immune response. Nat Genet 40:395-402

32. Burton PR, Clayton DG, Cardon LR et al (2007) Association scan of 14,500 nonsynonymous SNPs in four diseases identifies autoimmunity variants. Nat Genet 39:1329-1337

33. Harley JB, Alarcon-Riquelme ME, Criswell LA et al (2008) Genome-wide association scan in women with systemic lupus erythematosus identifies susceptibility variants in ITGAM, PXK, KIAA1542 and other loci. Nat Genet 40:204-210

34. Kozyrev SV, Abelson AK, Wojcik J et al (2008) Functional variants in the B cell gene BANK1 are associated with systemic lupus erythematosus. Nat Genet 40:211-216

35. Hafler DA, Compston A, Sawcer S et al (2007) Risk alleles for multiple sclerosis identified by a genomewide study. N Engl J Med 357:851-862 
36. Wilkin TJ (2006) The accelerator hypothesis: a unifying explanation for type-1 and type-2 diabetes. Nestle Nutr Workshop Ser Clin Perform Programme 11:139-150; discussion 150-133

37. Field SF, Howson JM, Smyth DJ, Walker NM, Dunger DB, Todd JA (2007) Analysis of the type 2 diabetes gene, TCF7L2, in 13,795 type 1 diabetes cases and control subjects. Diabetologia 50:212-213

38. Field SF, Howson JM, Walker NM, Dunger DB, Todd JA (2007) Analysis of the obesity gene FTO in 14,803 type 1 diabetes cases and controls. Diabetologia 50:2218-2220

39. Cervin C, Lyssenko V, Bakhtadze E et al (2008) Genetic similarities between latent autoimmune diabetes in adults, type 1 diabetes, and type 2 diabetes. Diabetes 57:1433-1437

40. Zeggini E, Scott LJ, Saxena R et al (2008) Meta-analysis of genomewide association data and large-scale replication identifies additional susceptibility loci for type 2 diabetes. Nat Genet 40:638-645

41. Kavvoura FK, Ioannidis JP (2008) Methods for meta-analysis in genetic association studies: a review of their potential and pitfalls. Hum Genet 123:1-14

42. Saxena R, Voight BF, Lyssenko V et al (2007) Genome-wide association analysis identifies loci for type 2 diabetes and triglyceride levels. Science 316:1331-1336

43. Scott LJ, Mohlke KL, Bonnycastle LL et al (2007) A genomewide association study of type 2 diabetes in Finns detects multiple susceptibility variants. Science 316:1341-1345
44. Zeggini E, Weedon MN, Lindgren CM et al (2007) Replication of genome-wide association signals in UK samples reveals risk loci for type 2 diabetes. Science 316:1336-1341

45. Galicia JC, Tai H, Komatsu Y, Shimada Y, Akazawa K, Yoshie H (2004) Polymorphisms in the IL-6 receptor (IL-6R) gene: strong evidence that serum levels of soluble IL-6R are genetically influenced. Genes Immun 5:513-516

46. Thorand B, Kolb H, Baumert J et al (2005) Elevated levels of interleukin-18 predict the development of type 2 diabetes: results from the MONICA/KORA Augsburg Study, 1984-2002. Diabetes 54:2932-2938

47. Hu FB, Meigs JB, Li TY, Rifai N, Manson JE (2004) Inflammatory markers and risk of developing type 2 diabetes in women. Diabetes 53:693-700

48. Lowe CE, Cooper JD, Brusko T et al (2007) Large-scale genetic fine mapping and genotype-phenotype associations implicate polymorphism in the IL2RA region in type 1 diabetes. Nat Genet 39:1074-1082

49. Gregory SG, Schmidt S, Seth P et al (2007) Interleukin 7 receptor alpha chain (IL7R) shows allelic and functional association with multiple sclerosis. Nat Genet 39:1083-1091

50. Marchini J, Howie B, Myers S, McVean G, Donnelly P (2007) A new multipoint method for genome-wide association studies by imputation of genotypes. Nat Genet 39:906-913 